\title{
Happily Ever after: The Use of Stories to Promote Positive Interventions
}

\author{
Daniel J. Tomasulo ${ }^{1}$, James O. Pawelski ${ }^{2}$ \\ ${ }^{1}$ Psychology Department, New Jersey City University, Jersey City, USA \\ ${ }^{2}$ Positive Psychology Center, University of Pennsylvania, Philadelphia, USA \\ Email: danielto@alumni.upenn.edu
}

Received September 21 $1^{\text {st }}$,2012; revised October 21 $1^{\text {st }}$, 2012; accepted November $17^{\text {th }}, 2012$

\begin{abstract}
People turn to myriad ways to achieve happiness, such as physical pleasures, relationships, or the achievement of goals. Success in these endeavors varies, however, and may not be sustainable. Recent advances in scientific research may be able to help, with a number of studies suggesting that people have the power to increase happiness through intentional activities. Narrative is one of the most pervasive and promising elements of positive interventions, and stories play a significant role both in psychological research and in application. A proposal is made that stories should be used more frequently as a vehicle to demonstrate and encourage the use of positive interventions, and a suggestion is made on how to collect and disseminate them.
\end{abstract}

Keywords: Happiness; Positive Interventions; Stories; Narrative; Narrative Psychology

\section{Introduction}

"Story is far older than the art of science and psychology, and will always be the elder in the equation no matter how much time passes." - Clarissa Pinkola Estes

Human beings desire to be happy. Most of our daily thoughts and actions have the end goal of achieving, maintaining or salvaging our happiness. Yet despite the species clamoring toward these goals since antiquity, a formula offering a consistent, reliable path toward their realization remains elusive. People turn to myriad ways to achieve happiness, such as physical pleasures, relationships, or the achievement of goals. Success in these endeavors varies, however, and may not be sustainable. As Adler (1962) has pointed out, the authors of the Constitution of the United States could only guarantee the right to pursue happiness. They were wise enough to realize they could not assure that it would be attained.

Throughout history, philosophers, priests, playwrights, selfhelp gurus and now researchers struggle to understand what happiness is and how we can have more of it in our lives. Yet each of these approaches offers a perspective that yields different advice. Aristotle, in the Nicomachean Ethics, describes a happy life as a good life. He claims that we can judge whether a life was happy only after it is over. The Bible tells us something different. In the Gospels, we are told that happiness must wait until we are in heaven: "How happy you are when men hate you and turn you out of their company...Be glad when that happens and jump for joy-your reward in Heaven is magnificent” (Luke, 6: p. 23). In Buddhism the Karmic cycle of cause and effect returns the soul to this life to continually rid the mind of delusions and desires. When this is accomplished, and a soul also becomes free of its aversions, the mind becomes still and the soul reaches a state called Nirvana. This can take several lifetimes.

Is there something we can do now without having to wait? What about being happy in this life? Waiting for others to evaluate our life when it is over, waiting until we get to heaven, or reincarnating until we get it right seems like happiness is being put on hold.

Recent advances in scientific research may be able to help, with a number of studies suggesting that people have the power to increase happiness through intentional activities. The new science of positive psychology is devoted to researching how people thrive and flourish. Historically, psychology has emphasized what is wrong with human beings and ways to help people cope with mental illness. This focus on alleviating suffering did not look much past getting people out of pain. Positive psychology adds something beyond recovery. It seeks to move toward happiness and well-being, not simply away from suffering.

Martin Seligman, former president of the American Psychological Association, made his 1998 presidential term a clear platform for the development of positive psychology (Seligman \& Csikszentmihalyi, 2000). The creation of positive interventions that can be tested for effectiveness is central to this effort and focus. A positive intervention is an intentional act that has the goal of increasing happiness. Seligman, Steen, Park, and Peterson (2005) have identified this emphasis in positive psychology by declaring: "The causal efficacy of happiness has focused our research group on one practical matter: intervenetions that build happiness" (p. 414). The application of positive interventions is important because among other benefits, research shows happier people live longer (Danner, Snowdon, \& Friesen, 2001); are kinder (Otake, Shimai, Tanaka-Matsumi, Otsui, \& Fredrickson, 2006); are more successful (Lyubomirsky, King, \& Diener, 2005); and have better relationships (Scinta \& Gable, 2007). The results from these studies and many others have prompted Seligman, Steen, Park, and Peterson (2005) to note: “...the efficacy of psychological interventions [is] in many ways the bottom line of work in positive psychology” (p. 432).

One of the most pervasive and promising elements of posi- 
tive interventions is narrative. Stories play a significant role both in psychological research and in application. A number of key positive interventions use participants' narratives as a component in the research (Danner, Snowdon, \& Friesen, 2001; Pennebaker, 1997, 2004; Seligman et al., 2005). Furthermore, three of the first five positive interventions reported on by Seligman and his colleagues (Seligman et al., 2005) involve the use of autobiographical narratives: The gratitude visit, you at your best, and three good things in your life. Other major positive intervention programs and research use storytelling as a central element in the means to deliver or facilitate the intervention. In fact, the Penn Resiliency Program (PRP), the world's most widely researched program for the prevention of depression, (Seligman, Ernst, Gillham, Reivich, \& Linkins, 2009) includes storytelling as a central component. The Master Resilience Training (MRT) program (Reivich, Seligman, \& McBride, 2011), is a face-to-face resilience training course, which is comprised of three component of preparation, sustainment, and enhancement. It is a central component of the Comprehensive Soldier Fitness Program, for the US Army, the world's largest consumer of positive psychology interventions.

In the pages that follow, we will explore in much more detail these and other uses of narrative in positive psychology research and application. In the first part of this paper we will discuss the role of positive interventions with an emphasis on how some interventions use stories. In the second part we will discuss contributions from narrative psychology on the influence stories and personal narratives have on well-being. In the final part, we will propose that stories with certain features and characteristics be used more frequently as a vehicle to demonstrate and encourage the use of positive interventions, and then suggest how to collect and disseminate them.

\section{Positive Interventions}

Michael Fordyce $(1977,1983)$, was one of the first to use randomized controlled trials in positive interventions. He is considered a pioneer in evidence-based positive psychology for introducing fourteen practices he referred to as "The 14 Fundamentals Program” (Fordyce, 1983: p. 484). A summary of these practices are: stay active and busy; increase time spent socializing; engage in productive, meaningful work; plan and organize; stop worrying; lower expectations and aspirations; develop positive thinking (be optimistic); stay in the here and now; work on a healthy personality; develop an outgoing, social personality; be yourself; eliminate both negative feelings and problems; emphasize close relationships; make happiness your number one priority. In seven studies he consistently found students who engaged in these exercises were happier than those who did not. This was one of the first demonstrations of using positive interventions to increase positive feelings. While these practices are rudimentary suggestions, they encapsulate the seeds of more defined, effective interventions.

In a landmark article on the effectiveness of positive interventions, Seligman, Steen, Park, and Peterson (2005) reported on the gratitude visit and four other interventions, each of which was compared to the placebo condition of participant's journaling about early memories. The study was an Internet-based experiment conducted over the course of a week. The other interventions had participants write down each night three things that had gone well during the day and what caused them to happen (three good things); write about when they felt they were at their best and reflect on their strengths (you at your best); and in the final two conditions participants were asked to take a survey about character strengths. In one condition they had to use these strengths in a new way, and in the other condition to use their top five strengths more often. The impressive results are best described in the author's own words:

Two of the exercises-using signature strengths in a new way and three good things-increased happiness and decreased depressive symptoms for six months. Another exercise, the gratitude visit, caused large positive changes for one month. The two other exercises and the placebo control created positive but transient effects on happiness and depressive symptoms. Not surprisingly, the degree to which participants actively continued their assigned exercise on their own and beyond the prescribed one-week period mediated the long-term benefits (Seligman et al., 2005: p. 416).

Lyubomirsky, Sheldon, and Schkade (2005) also support the value of intentional acts. They have put forth a sustainable happiness model that invites interventions as a viable way to both increase and maintain happiness. This model has three components: a set point, which is the core happiness value determined by our makeup; a life circumstance factor; and specifically chosen intentional acts (interventions). While the set point accounts for about 50 percent of our happiness trait and 10 percent of it is due to the situation, these interventions can account for 40 percent of the intentional activities leading to happiness (Lyubomirsky, 2009; Lyubomirsky et al., 2005).

The proliferation of conferences and journals now supports a steady stream of data about the ways and means of attaining well-being. Evidence suggests that positive interventions can increase well-being and reduce depressive symptoms (Seligman \& Csikszentmihalyi, 2000; Seligman et al., 2005; Seligman, 1992, 2002, 2011; Sin \& Lyubomirsky, 2009), and that these changes can reach a critical mass or tipping point that leads to a positive spiral (Frederickson, 1998, 2000, 2001, 2004, 2009; Fredrickson \& Levenson, 1998; Fredrickson \& Joiner, 2002; Fredrickson et al., 2008). Further, these increases may be sustainable over time (Lyubomirsky et al., 2005; Fredrickson, Cohn, Coffey, Pek, \& Finkel, 2008).

\section{Concerns about Positive Interventions}

In spite of the robust and broad support for positive psychology interventions, critics caution that their use is not a panacea. They argue that positive psychology rests on a flawed assumption: that universally beneficial traits and processes for well-being exist. This critique was most recently put forth by McNulty and Fincham (2012) who asserted that “...positive psychologists have not paid enough attention to the interpersonal context in which people spend much of their lives" (p. 101). The authors offer an important perspective by evaluating positive psychology research with an emphasis on the context under which an intervention will be optimal. This includes arguing that positive interventions must be tested on both healthy and unhealthy people, and understanding that traits and processes are neither positive nor negative and can have varying effects. This viewpoint maintains that the success of a positive intervention depends not only on what the intervention is, but how and to whom it is delivered. This would align with the research discussed above pertaining to the gratitude and kindness interventions by Boehm and Lyubomirsky (2009).

This contribution notwithstanding, McNulty and Fincham go 
on to point very specifically to the literature on forgiveness as being flawed, but this criticism seems unwarranted because it is based on inaccurate generalizations about positive psychology research. They write, "Most existing research, much of which is based primarily on people not facing physical abuse..." (italics added, p. 101). While this is true, they then ignore research that does examine positive interventions with people who have been abused. Positive psychologists have studied forgiveness with regard to abusive relationships in major peer-reviewed journals. Additionally, they have made recommendations for clinicians to incorporate their findings into direct interventions. In spite of McNulty and Fincham's comments, positive psychologists have paid attention to "the interpersonal context in which people spend much of their lives”.

Worthington and Luskin, for example, both leaders in the field of forgiveness, recommend caution when employing forgiveness in an abusive relationship. In a meta-analysis, Wade and Worthington (2005) surveyed 14 empirical studies of applied research on forgiveness interventions. This revealed a consensus on four intervention types: remembering the hurt in a supportive environment; building empathy for the perpetrator; acknowledging one's own transgressions; and encouraging forgiveness of the offender. Further, these findings were demonstrated to be effective across subjects, methods and theoretical approaches. An earlier study found that a meta-analysis of subjects, facilitators and interventions suggest that the act of forgiveness interventions were better than placebo treatments (such as discussion groups), suggesting that intervening to promote forgiveness is more important than the actual content of the intervention. Worthington and Wade (1999) as well as Wade and Worthington (2005) make specific notations on their findings concerning forgiveness in the face of abuse. They specifically noted:

Misunderstandings can be particularly troublesome for victims of severe abuse. People who confuse forgiveness (i.e., an internal change in thoughts, emotions, or motivations) with reconciliation (i.e., restoring a relationship) may not see that a victim can forgive without reconciling. Such confusion may lead to irresponsibly encouraging clients either to accept abusive situations or to retain the angry and resentful emotions to protect them from future harm. However, understood in terms defined by the reviewed interventions, forgiveness can occur and the victim can still hold the offender accountable, see the offender in realistic terms, and make wise decisions about whether to return to the relationship (p. 165).

The Stanford Forgiveness Project, Forgive for Good: A Proven Prescription for Health and Happiness (Luskin, 2001) is one example of a direct application of research that continues to gain empirical support (Harris et al., 2006). These studies have been distilled into a trade paperback and accompanying successful workshops. Luskin (2001) explicitly included the research and intervention strategies that echo the writing of Wade and Worthington (2005). McNulty and Fincham (2012) do not include a single reference to his wealth of research and applied practice.

McNulty and Fincham (2012) might have had a more balanced perspective had they reviewed this work. By not doing so, they make two serious errors in argument. First, they make the assumption that positive psychologists believe character traits and processes are universally beneficial. Second, they fail to include the work of leaders in the field of forgiveness who have already identified and addressed their concerns.

\section{Using Stories to Facilitate Positive Interventions}

Stories, autobiographical narratives, journals, letters and reflective descriptions are some of the ways researchers are using to deliver, enhance, clarify or identify a positive intervention. In this section we will review the Penn Resilience Program (PRP) and the Nun Study, two of the most prominent research endeavors in the field of positive psychology, from the perspective of narrative. We will pay particular attention to the value the effective use of these and similar methods can have.

Martin Seligman, Jane Gillham and Karen Reivich at the PRP are using a variety of storytelling methods to help students cope with depression and anxiety (Seligman et al., 2005). There has been a steady rise in adolescent depression over the past several decades and the PRP was designed to help students cope with the daily struggles of being a teenager (Seligman et al., 2009). At the program's core is the use of story-conveying methods to show the problem, the intervention, and the correction. The PRP is the world's most widely researched depression prevention program. To date there have been twenty-one studies with children and young adults ranging from ages 8 to 22 . The findings from these studies have broadly influenced not only the field of education (Seligman et al., 2009), but have become the foundation for the development of the Master Resilience Training (MRT) program employed by the US Army (Reivich et al., 2011).

The specific focus has been to reduce a sense of helplessness while preventing or reducing depression and anxiety and increasing optimism. The research found there were fewer conduct problems reported and those involved displayed better physical health. The PRP draws heavily on the Adversity-Beliefs-Consequences (A-B-C) model (Ellis, 1962), in which beliefs about events affect our emotions and behavior. Students are introduced to coping skills and given information on situational dilemmas through the use of short stories, skits, cartoons, and role-plays. From the work at PRP, a more ambitious project was launched. The Strath Haven Positive Psychology Curriculum was designed to help students both identify and enhance the use of their signature character strength (Seligman et al, 2009). In this study, 347 14- and 15-year-olds were randomly assigned to a language arts class. Only half received a positive psychology curriculum. Those who were in the experimental group kept a narrative journal of their experiences and engaged in weekly discussions about character strengths and applying positive psychology in their own lives. These discussions were their shared stories. For example, they discussed three good things that happened each day for a week and answered the questions: "Why did this good thing happen?" "How can you have more of this good thing in the future?” The power of stories to teach and inspire was also applied more directly through the use of classic literature. Not only did the students in the experimental group have to report on the character strengths in themselves and their friends, they had to identify those strengths in literary figures in their effort to overcome obstacles in the story.

In a blind review, the study found empathy, cooperation, assertiveness and self-control got better with the positive psychology group, while the strengths of curiosity, love of learning, and creativity were also improved. Mothers reported fewer conduct problems, and students' reports of engagement and enjoyment in school were higher. This study showed well-being enhanced classroom learning. Central to this process was narra- 
tive journaling, sharing stories and reading literature through the lens of character strength and resilience. Seligman and his colleagues sought to shift the culture of an entire school toward positive psychology. While not a research study, the Geelong Grammar School Project uses many of the features already described (Seligman et al., 2009). But there were two important additions with regard to the use of stories. First, as part of the English literature curriculum, the process of analyzing literary figures in novels with regard to character strengths and resiliency was established. Second, the daily religious services highlighted stories, which reinforced character strengths discussed elsewhere in the curriculum; stories from scriptural passages were used to teach positive psychology.

The use of stories to convey issues, interventions, and insights are at the base of these studies and project. They are an integral part of the delivery and facilitation of the positive interventions such as the A-B-C model and identification of signature strengths. They are used to teach and strengthen learning of positive experiences. In short, stories are woven into the fabric of some of the best and most well-known research on positive interventions.

In the Nun Study ${ }^{1}$, researchers Danner, Snowdon, and Friesen (2001) analyzed the emotional content of handwritten autobiographies of nuns seeking entry into the convent when their average age was 22 and found a strong correlation between positive emotional content and longevity more than fifty years later (Tomasulo, 2010). The researchers hypothesized that analyzing autobiographies the nuns had written as young women would reveal their emotional temperament and that a positive verses a negative expression would predict the nuns' health and longevity. The religious sisters were ideal subjects because of the profound similarities in their physical lives. Nuns have similar, regularized diets, live together in similar surroundings, do not have children, and do not smoke or drink to excess. In other words, their physical backgrounds and conditions are very well controlled, and the impact of their early emotional disposition and risk of mortality in later life could be more directly determined. Researchers coded the autobiographies in terms of positive, negative and neutral words, ultimately focusing on three features of these statements: positive emotion words, sentences, and variety of positive emotional expressions. The analysis was done roughly 60 years later, when the nuns were between 75 and 94 years old. By that time 42 percent of them had died. The nuns who expressed more positive emotions lived, on average, a decade longer than their less cheerful peers. By the average age of 80,60 percent of the least positive nuns had died. The probability of survival was consistently in favor of the more positive nuns. There seems to be a direct relationship between positivity and longevity: The stories we tell about ourselves are related to our health and happiness.

This landmark study was not just about happiness and health, it was actually about Alzheimer's disease. Researchers considered the effect these positive approaches toward life might have on the devastating effects of dementia. Over a decade after the original study was conducted, ongoing research about these nuns is more than curious. Scientists have harvested the brains of the sisters who have died and have archived medical, dental

\footnotetext{
${ }^{1} \mathrm{~A}$ version of the material in this section appears in a blog written by one of the authors

(DJT):http://psychcentral.com/blog/archives/2010/10/27/proof-positive-can-
} heaven-help-us-the-nun-study-afterlife/ and academic records. Research on the sisters' brains suggests not only that those with a positive outlook on life enjoyed less disease and lower mortality rates but also that these nuns may have had a natural immunization against the ravages of Alzheimer's disease. About half of the brains are free of Alzheimer's, and researchers have found a strong and seemingly causal correlation. The nuns with positive perspectives on life were free of the disease, and those with negative outlooks had symptoms of dementia. The autobiographical narratives the nuns told about themselves in the early part of their lives were associated with their well-being throughout. In this study, the independent variable was the way the story was told, and this variable was correlated with emotional temperament, which predicted better health and longevity.

\section{Stories, Morality and Empathy}

Stories influence us because we can relate to them and this ability seems to be something we are able to do very early in life. When someone tells us a story about her troubles we are moved by her plight; when it is about her triumphs we celebrate with them. Robert Coles (1989, 2000) a Harvard psychiatrist and Pulitzer Prize winner, places great value on narratives to understand the human condition. In the Call of Stories (1989) he posits that we learn almost all of our moral lessons through personal stories and literature. In the Moral Life of Children (1986/2000) he notes that it is the stories children tell each other that provides them with a moral compass. It is by listening to each other that they decide what is right and wrong.

But stories are not only about morality. They can influence our well-being in a variety of ways. Psychologists Paul Bloom (2010) and Jonathan Haidt (2006, 2012) believe there is great power in the use of story as a vehicle to extend empathic understanding. They believe the development of empathy through the use of story may be part of the core dynamic inherent in why stories work. Bloom's work with his colleagues Karen Wynn and Kiley Hamlin (Hamlin, Wynn, \& Bloom, 2007; Kuhlmeier, Wynn, \& Bloom, 2003) used a variety of one-act morality plays with good guys and bad guys interacting with various objects. The infants witnessed these interactions, these stories, and it influenced how they behaved toward these characters by preferring them as choices afterward. In subsequent studies the researchers used younger and younger infants and they repeatedly found the infants preferring the good guy: They are sensitive to the positive and negative nature of third-party interventions. If watching these moral stories can influence how children behave toward the character at such early ages it emphasizes the power and potential of human ability to appreciate story dynamics and learn from them. Understanding which features are innately determined as "good" and which are culturally established will help strengthen innate vs. learned traits related to well-being. As McAdams (2008) says: "They implicitly understand that a story's characters act in accord with goals” (p. 250).

\section{Personal Narrative}

While there are many different types of stories that may be helpful to positive psychology, space limitations will allow us to focus only on the personal narrative. The stories people tell themselves and others can influence well-being. Many kinds of stories can affect us. From Aesop's fables to the book of Exo- 
dus and the myths analyzed by Joseph Campbell in The Hero with a Thousand Faces (2008), stories have long been used to tell people what to value, how to live, and what has moral worth. But one type of story-the personal narrative, the telling of a story about a personal memory-seems to have a unique influence. It helps to integrate the person narrating it while conveying understanding through empathy. The understanding of the way stories shape lives is the subject of a broad area of study known as narrative psychology. This section will focus on theory and research about how personal narratives can be helpful to those who tell them, and what makes them valuable to those who hear them.

The study of personal narratives recently has become a central topic in personality research. In part this is due to personality theorists writing that the self develops over time (Maslow, 1964; Moreno, 1964; Erikson, 1963). As Dan McAdams (1996), one of the leading theorists in this domain, points out:

It is no coincidence that the rise of the novel as a Western art form and the growing popularity of journals, diaries and other autobiographical devices neatly parallel the rise of modernity in the West, for making sense of the modern self as it changes over time centrally involves the construction of self-narratives (p. 298).

McAdams writes further, "The stories people tell about their lives is no longer a promising new direction for the future of personality psychology. Instead personal narratives and the life story have arrived" (McAdams, 2008: p. 242, italics in text). This emphasis rests on what McAdams has called "narrative identity," which he defines as the "internalized, evolving, and integrative story of the self” (p. 242). In this understanding, the construction and development of the self is a blend of both the storyteller and the stories told (Bauer, McAdams, \& Pals, 2008).

Pennebaker $(1997,2004)$ found that integration is central to the process of writing about negative episodes in life and offers research to show how writing about traumatic events can improve the immune system. In his book, Writing to Heal: A Guided Journal for Recovering from Trauma and Emotional Upheaval (2004) he shows how this writing can improve not only the immune system, but also grades and lives. In an effort to improve the benefits of writing about negative nuclear episodes, Pennebaker and his colleagues (Pennebaker, Francis, \& Booth, 2001) have developed a text analysis program called Linguistic Inquiry and Word Count (LIWC). This helps identify categories of words such as words expressing negative emotion (sad, angry), words reflective of positive emotion (happy, laugh), causal terms (because, reason), and insight words (understand, realize). Pennebaker and Chung (2007) report on a series of studies analyzed using LIWC and found that people who wrote about experiences using a greater percentage of positive emotion words had health improved. The use of LIWC can be used to identify those stories having the most beneficial impact.

The results about writing about positive and negative experiences are mixed, but very interesting. King \& Miner (2000) researched different participants exposed to three conditions. The first condition is writing about a trauma in their life. The second condition is writing about benefits from the trauma experience. The third condition is a mixed condition where participants write about the trauma first, then switch to the perceived benefits from the traumatic experience. The trauma only and benefits-only participants had health improvements. The mixed condition did not. Pennebaker and Chung (2007) theorize this may be because the participants were not able to write about their trauma and then integrate thinking and writing about the benefits. Another study found that an extensive review and processing life events has a differential effect with regard to measures of well-being. Lyubomirsky, Sousa, and Dickerhoff (2006) found when one group of subjects wrote about negative events participants reported higher well-being. But this influence was reversed when other subjects were asked to write about positive events. This intervention led to reduced wellbeing. The authors theorized that the act of organizing thoughts helped with the integration of negative life events in a way similar to what Pennebaker has argued $(1997,2005)$. However, trying to organize thought about only positive experiences may interrupt the cognitive process associated with savoring positive emotions. In contrast, Laura King (Burton \& King, 2004) has also studied intensely positive experiences (IPE) when compared to control (trivial) topics and has found improved mood and fewer medical visits for the participants writing about IPEs. These are intriguing differences and more research is needed on the narrative effect of writing only about a positive experience. McAdams's research and comments (1996, 1998, 2001) analyzed and categorized the life stories of more than 200 individuals. He proposes a framework for understanding the structure and content of life stories via narrative tone, imagery, theme, ideological setting, and endings. But there are two additional features of the structure and content he describes that we believe have particular relevance for positive psychology: imagoes and what he refers to as "nuclear episodes."

The imago, according to McAdams (1996), is the idealized version of the protagonist telling the story and is a characterization of a possible self, "the good boy or girl." As life stories are psychosocial constructions, the tale must have meaning in the culture as well as to the person telling it. Stories of positive experiences may be a version of a best possible self. It seems likely that the structure and content of the narrative will have that of an imago-a positive version of the self that others can relate to within the culture.

Alternately, a nuclear episode is a life scene that is typically high, low, beginning, ending, or a turning point. It can be an emblematic truth about a person, or a declaration of profound transition. These are typically more powerful scenes because they stand out in our memory. For better or worse these powerful internalized scenes inform an individual's identity. In the telling of these nuclear episodes others can be inspired. Both of these story motifs reflect what McAdams $(2006,2008)$ identifies as the redemptive self. He argues the redemptive-self stories that arc from tragedy to triumph are most often generative in nature. They tell a story with a message designed to promote well-being in future generations and the world in which they live. In other words, McAdams (2008) believes the "reflective self is a narrative model of the good life” (p. 255).

McAdams (2001) believes integration is the main function of a life story. He proposes that as we look at how narrative influences the self, the focus should be on dispositional traits of personality and the social and cognitive features of human behavior (McAdams, 1996, 2001). Within his proposed framework he believes it is the psychosocial construction of life stories that creates an identity. We become who we are via our life stories, but this is a two-way street: People tell stories about themselves in the act of forming their own identity, and in doing so help others make sense of their own lives.

Roy Baumeister, a leading figure in the field of positive psychology, agrees with McAdams (Baumeister \& Wilson, 
1996), and offers that the life stories we tell and are told string together to form meaningful patterns with a unique bias in their formulation. The bias is along the lines of our need for meaning. Baumeister and Wilson (1996) identify four such needs: Purpose (goals and fulfillment); value and justification (seeing one's self as good); efficacy (making outcomes happen); and self-worth (accomplishments). He believes a story without all four of these will be unsatisfactory. In other words, to regard our life as meaningful we look for stories and tell ourselves narratives that have these four elements.

\section{The Use of Stories to Promote Positive Interventions}

Martin Seligman (2011) has set a goal for fifty-one percent of the world to be flourishing by the year 2051. To achieve this, people will need to be educated and inspire people to use positive interventions. Stories seem a natural means for promoting this effort. Storytelling is woven into the human psyche through our cultures and development, stories are embedded into the facilitation of positive interventions, and the personal narrative can provide a vehicle for recovery from negative emotions while helping to integrate meaning in our lives. Tal Ben-Shahar, who between 2004 and 2008 taught the most popular course in the history of the Harvard psychology department, sees stories as essential to the teaching of positive psychology:

Stories form an important part of every class when teaching positive psychology topics, regardless of whether they are personal stories or stories about other people. Each of the topics discussed in the course includes presenting a story as an introduction to research on the topic, followed by an application. In other words, the story "sets the stage" for a study or a theory, which in turn leads to action-the implications of the ideas presented and how they can be implemented in "real-life". It is important to tell stories that will inspire the students, move them and enable them to better remember the material. Stories can also bring research to life (Russo-Netzer \& Ben-Shahar, 2011: p. 472).

One among several purposes behind the use of stories in positive psychology is to bring research to life. We propose the development of an Internet site for the collection of stories to inspire people to use evidence-based positive interventions. Based on the research done in this paper successful stories will include at least some of these attributes. The story should: be an example of a positive intervention in action, be a personal narrative, activate empathy and engagement, be nuclear in that it reflects a high or low point - a beginning or an end, be an imago (a positive version of the self that others can relate to within the culture), be a reflective self and redemptive having the arc of tragedy to triumph. In addition, the stories should evoke meaning by incorporating elements proposed by Baumeister and Wilson (1996): purpose (goals and fulfillment), value and justification (seeing one's self as good), efficacy (making outcomes happen), and self-worth (accomplishments). A website would allow people to submit stories that follow the above criteria, have these stories categorized according to the positive interventions they promote, and provide an ever-increasing resource for educators, researchers, clinicians and coaches.

Like all good stories, we end where we began. "Happily ever after" is traditionally the ending of a fictional story. But in positive psychology, it is the beginning of the real story, be- cause the writing and rewriting of the narratives of our lives is one of the most powerful means available for moving toward greater happiness.

\section{Acknowledgements}

This article is dedicated to Chris Peterson who died unexpectedly on October 9th, 2012. He was one of the leading researchers in the field of positive psychology, and a friend, mentor, and colleague to many. He was a great storyteller, and a person about whom many inspirational stories will be told.

\section{REFERENCES}

Adler, M. J., \& Encyclopaedia Britannica Educational Corporation (1962). Aristotle's ethics: The theory of happiness. Chicago, IL: Encyclopædia Britannica Educational Corporation.

Bauer, J. J., McAdams, D. P., \& Pals, J. L. (2008). Narrative identity and eudaimonic well-being. Journal of Happiness Studies, 9, 81-104. doi:10.1007/s10902-006-9021-6

Baumeister, R. F., \& Wilson, B. (1996). Life stories and the four needs for meaning. Psychological Inquiry, 7, 322-325. doi:10.1207/s15327965pli0704 2

Bloom, P. (2010). How pleasure works. New York: Norton.

Boehm, J. K., \& Lyubomirsky, S. (2009). The promise of sustainable happiness. Handbook of Positive Psychology, 667-677.

Burton, C. M., \& King, L. A. (2004). The health benefits of writing about intensely positive experiences. Journal of Research in Personality, 38, 150-163. doi:10.1016/S0092-6566(03)00058-8

Campbell, J. (2008). The hero with a thousand faces. New York: New World Library.

Coles, R. (1989/2000). The moral life of children. Boston, MA: Atlantic Monthly Press.

Coles, R. (1989). The call of stories: Teaching and the moral imagination. Boston, MA: Mariner Books.

Danner, D., Snowdon, D., \& Friesen, W. (2001). Positive emotions in early life and longevity: Findings from the nun study. Journal of Personality and Social Psychology, 80, 804-813. doi:10.1037/0022-3514.80.5.804

Ellis, A. (1962). Reason and emotion in psychotherapy. New Jersey: Citadel.

Erikson, E. (1963). Childhood and society (2nd ed.). New York: Norton.

Fordyce, M. W. (1977). Development of a program to increase personal happiness. Journal of Counseling Psychology, 24, 511-520. doi:10.1037/0022-0167.24.6.511

Fordyce, M. W. (1983). A program to increase happiness: Further studies. Journal of Counseling Psychology, 30, 483-498. doi:10.1037/0022-0167.30.4.483

Fredrickson, B. L. (2009). Positivity: Groundbreaking research reveals how to embrace the hidden strength of positive emotions, overcome negativity, and thrive. New York: Crown Archetype.

Fredrickson, B. L. (2004). Gratitude, like other positive emotions, broadens and builds. In R. A. Emmons, \& M. E. McCullough (Eds.), The psychology of gratitude (pp. 145-166). New York: Oxford University Press. doi:10.1093/acprof:oso/9780195150100.003.0008

Fredrickson, B. L. (1998). What good are positive emotions? Review of General Psychology, 2, 300-319. doi:10.1037/1089-2680.2.3.300

Fredrickson, B. L. (2001). The role of positive emotions in positive psychology: The broaden-and-build theory of positive emotions. American Psychologist, 56, 218-226. doi:10.1037/0003-066X.56.3.218

Fredrickson, B. L. (2000). Extracting meaning from past affective experiences: The importance of peaks, ends, and specific emotions. Cognition and Emotion, 14, 577-606. doi:10.1080/026999300402808

Fredrickson, B. L., Cohn, M. A., Coffey, K., Pek, J., \& Finkel, S. M. (2008). Open hearts build lives: Positive emotions, induced through meditation, build consequential personal resources. Journal of Personality and Social Psychology, 95, 1045-1062. 


\section{J. TOMASULO, J. O. PAWELSKI}

doi:10.1037/a0013262

Fredrickson, B. L., \& Joiner, T. (2002). Positive emotions trigger upward spirals toward emotional well-being. Psychological Science, 13, 172-175. doi:10.1111/1467-9280.00431

Fredrickson, B. L., \& Levenson, R. W. (1998). Positive emotions speed recovery from the cardiovascular sequelae of negative emotions. Cognition and Emotion, 12, 191-220. doi:10.1080/026999398379718

Haidt, J. (2006). The happiness hypothesis: Finding modern truth in ancient wisdom. New York: Basic Books.

Haidt, J. (2012). The righteous mind: Why good people are divided by politics and religion. New York: Penguin.

Hamlin, J. K., Wynn, K., \& Bloom, P. (2007). Social evaluation by preverbal infants. Nature, 450, 557-559. doi:10.1038/nature06288

Harris, A., Luskin, F. M. Benisovich, S. V., Standard, S., Bruning, J., Evans, S., \& Thoresen, C. (2006) Effects of a group forgiveness intervention on forgiveness, perceived stress and trait anger: A randomized trial. Journal of Clinical Psychology, 62, 715-733. doi:10.1002/jclp.20264

King, L. A., \& Miner, K. N. (2000). Writing about the perceived benefits of traumatic events: Implications for physical health. Personality and Social Psychology Bulletin, 26, 220-230. doi:10.1177/0146167200264008

Kuhlmeier, V., Wynn, K., \& Bloom, P. (2003). Attribution of dispositional states by 12-month-olds. Psychological Science, 14, 402-408. doi:10.1111/1467-9280.01454

Lieblich, A., McAdams, D. P., \& Josselson, R. (2004). Healing plots: The narrative basis of psychotherapy. Washington DC: American Psychological Association. doi:10.1037/10682-000

Luskin, F. M. (2001). Forgive for good: A proven prescription for health and happiness. New York: Harper One.

Lyubomirsky, S. (2008). The how of happiness: A scientific approach to getting the life you want. New York: Penguin.

Lyubomirsky, S., King, L., \& Diener, E. (2005). The benefits of frequent positive affect: Does happiness lead to success? Psychological Bulletin, 131, 803-855. doi:10.1037/0033-2909.131.6.803

Lyubomirsky, S., Sheldon, K. M., \& Schkade, D. (2005). Pursuing happiness: The architecture of sustainable change. Review of General Psychology, 9, 111-131. doi:10.1037/1089-2680.9.2.111

Lyubomirsky, S., Sousa, L., \& Dickerhoof, R. (2006). The costs and benefits of writing, talking, and thinking about life's triumphs and defeats. Journal of Personality and Social Psychology, 90, 692-708. doi:10.1037/0022-3514.90.4.692

Maslow, A. H. (1968). Toward a psychology of being. New York: Van Nostrand.

McAdams D. P. (2008). Personal narratives and the life story. Handbook of Personality: Theory and Research (3rd ed., pp. 241-261). New York, NY: Guilford.

McAdams, D. P. (1996). Personality, modernity, and the storied self: A contemporary framework for studying persons. Psychological Inquiry, 7, 295-321. doi:10.1207/s15327965pli0704_1

McAdams, D. P. (2001). The psychology of life stories. Review of General Psychology, 5, 100-122. doi:10.1037/1089-2680.5.2.100

McNulty, J. K., \& Fincham, F. D. (2012). Beyond positive psychology? Toward a contextual view of psychological processes and well-being. American Psychologist, 67, 101-110. doi:10.1037/a0024572

Moreno, J. L. (1964). The first psychodramatic family. New York: Beacon House.

Otake, K., Shimai, S., Tanaka-Matsumi, J., Otsui, K., \& Fredrickson, B. (2006). Happy people become happier through kindness: A counting kindness intervention. Journal of Happiness Studies, 7, 361-375. doi:10.1007/s10902-005-3650-z

Pennebaker, J. W. (1997). Writing about emotional experiences as a therapeutic process. Psychological Science, 8, 162-166. doi:10.1111/j.1467-9280.1997.tb00403.x

Pennebaker, J. W. (2004). Writing to heal: A guided journal for recovering from trauma and emotional upheaval. New York: New Harbinger.

Pennebaker, J. W., Francis, M. E., \& Booth, R. J. (2001). Linguistic inquiry and word count: LIWC. Mahwah, NJ: Lawrence Erlbaum Associates,

Pennebaker, J. W., \& Chung, C. K. (2007). Expressive writing, emotional upheavals, and health. In H. Friedman, \& R. Silver (Eds.), Handbook of health psychology (pp. 263-284). New York, NY: Oxford University Press.

Russo-Netzer, P., \& Ben-Shahar, T. (2011). Learning from success: A close look at a popular positive psychology course. The Journal of Positive Psychology, 6, 468-476. doi:10.1080/17439760.2011.634823

Reivich, K. J., Seligman, M. E. P., \& McBride, S. (2011). Master resilience training in the US Army. American Psychologist, 66, 25-34. doi:10.1037/a0021897

Scinta, A., \& Gable, S. L. (2007). Automatic and self-reported attitudes in romantic relationships. Personality and Social Psychology Bulletin, 33, 1008-1022. doi:10.1177/0146167207301013

Seligman, M. E. P. (1992). Learned optimism. New York, NY: Pocket Books.

Seligman, M. E. P. (2002). Authentic happiness: Using the new positive psychology to realize your potential for lasting fulfillment. New York, NY: Free Press.

Seligman, M. E. P. (2011). Flourish: A visionary new understanding of happiness and well-being. New York, NY: Free Press.

Seligman, M. E. P., \& Csikszentmihalyi, M. (2000). "Positive psychology: An introduction”: Reply. American Psychologist, 56, 89-90. doi:10.1037/0003-066X.56.1.89

Seligman, M. E. P., Steen, T. A., Park, N., \& Peterson, C. (2005). Positive psychology progress: Empirical validation of interventions. American Psychologist, 60, 410-421.

doi:10.1037/0003-066X.60.5.410

Seligman, M., Ernst, R., Gillham, J., Reivich, K., \& Linkins, M. (2009). Positive education: Positive psychology and classroom interventions. Oxford Review of Education, 35, 293-311. doi:10.1080/03054980902934563

Sin, N. L., \& Lyubomirsky, S. (2009). Enhancing well-being and alleviating depressive symptoms with positive psychology interventions: A practice-friendly meta-analysis. Journal of Clinical Psychology, 65, 467-487. doi:10.1002/jclp.20593

Tomasulo, D. (2010). Proof positive: Can heaven help us? The nun study-Afterlife. Psych Central.

http://psychcentral.com/blog/archives/2010/10/27/proof-positive-can -heaven-help-us-the-nun-study-afterlife/

Wade, N. G., \& Worthington Jr., E. L. (2005). In search of a common core: A content analysis of interventions to promote forgiveness. Psychotherapy: Theory, Research, Practice, Training, 42, 160-177. doi:10.1037/0033-3204.42.2.160

Worthington Jr., E., \& Wade, N. G. (1999). The psychology of forgiveness and unforgiveness and implications for clinical practice. Journal of Social and Clinical Psychology, 18, 385-418. doi:10.1521/jscp.1999.18.4.385 